\title{
Development of the paradigm of negative affixes in the English language: cognitive and diachronic aspects
}

\section{P. Trutyak}

Chernivtsi National University after Yuriy Fedkovych

Corresponding author. E-mail: irynatrutiak@gmail.com

Paper received 24.10.18; Accepted for publication 30.10.18.

\section{https://doi.org/10.31174/SEND-Ph2018-182VI53-14}

\begin{abstract}
The article is an attempt to combine methods of the historical comparative approach with ones of the cognitive approach. In the course of the investigation a diachronic paradigm of the negative affixes in Old, Middle and Modern English periods has been constructed. It has been suggested that the paradigm increased from 8 to 17 affixes. Within it in all the periods we distinguish 5 groups with main 5 negative tints of the meaning, which correlate with the meanings of the lexical semantic variants of the adjective "negative". Such phenomenon in Linguistics is called isomorphism of the units on different language levels.
\end{abstract}

Keywords: etymological analysis, definition, negative affixes, diachronic, isomorphism.

In Modern Linguistics to elucidate some diachronic issues attempts of combining traditional technics of HistoricalComparative method with new methods of Cognitive Linguistics have been made. In this article, which is one of such attempts, a brief historical review on the formative processes of the language units expressing negation, is made. It focuses on the correlation of the meaning of the word "negative" with other negative morphemes and analyzes the way it interacts with them.

The semantics and functional properties of the words with negative affixes have been in the focus of the investigation of O. Yespersen, C. Delmas, N. Marchand, K. Zimmer, A. Wierzbicka and others.

In the course of the language development its lexis undergoes most radical changes, as a result of close language contacts new words are borrowed, new affixes with them. The paradigm of negative affixes in Modern English somewhat differs from one in Old English due to both inner phonetic, semantic and grammatical changes and outer contacts with other Germanic languages, as well as with Latin, French and Celtic. The meanings of negative affixes vary within a broad range of semantic components (for example, of opposite or false action), they have their special grammatical combinability (for example, -less is added only to adjectives and their derivative nouns).

In modern linguistics there are discrepancies as for the structure or composition of negative affixes paradigm. So, R. Quirk, S. Greenbaum, G. Leech [12, p.982] in their classification define un-, in- (ir-, il-, im-), dis-, non-, a- as negative prefixes, at the same time they emphasize that beside these ones there are others, which have negative implication: reversative-privative un-, de-, dis- and prefixes of opposition anti-, counter-. Prefixes mis-, mal-, pseudo-, false- are considered stylistic means for expressing pejorative attitude. Suffix -less is also considered to be a negative marker. S. Leontieva [5, p.6] brings such a list of negative affixes: dis-, de-, mis-, anti-, non-, -less, un-. We believe, such variation in the scope of negative affixes is connected with poly-semantic nature of the adjective "negative" in relation to monosemantic noun "negation".

The objective of the article is to reveal the connection between meanings of the lexical-semantic variants of the adjective "negative" with the semantics of the negative affixes in the English language. In the course of the investigation 1) a comparative analysis of the definitions of the adjective "negative" according to 5 explanatory dictionaries of the English language has been made, 1) the diachronic paradigm of negative affixes in the three historical periods of English has been reconstructed, 2) both data compared and analyzed. The method of the etymological analysis of the morphemes with negative implication, the historical-comparative method of the reconstruction of their paradigm in diachrony in combination with the method of the definitions of the adjective "negative" have been applied.

The article is performed on the material of the etymological dictionaries of Germanic languages, etymological and explanatory dictionaries of the English language with some references to the dictionaries of Old French, Anglo-Saxon and Irish-English dictionaries.

1) "Lexical meaning includes 3 main macro-components: semantics, pragmatics and syntax. The word meaning in modern lexicography is outlined with the help of the analysis, which techniques presupposes classification on the basis of certain contextual feature word clusters, their grouping into subclasses which serve as basis for splitting the word semantics into "areas", called "meanings" or "lexical semantic variants of the word" [7, p.59]. These "areas" are indexed in the dictionaries and marked as description chains, semantically connected with the defined word. Thus, comparing semantics of words according to their word definitions, we compare the degree of similarity or divergence of their semantic, lexical or syntactic combinability.

To get reliable results of the word meaning study several or many dictionaries are selected. In the present investigation the definitions of "negative" from 5 dictionaries (see the table below) are compared. To make the procedure of comparing lexical meanings easier componential analysis of all the lexemes in the entry "negative" according to 5 dictionaries [2, p.882], [3, p.956], [8, p.907], [9, p.778], has been performed. Then components with common meanings were combined in "generalized" lexemes, then their ranges were defined. The range index (the ordinal number) shows frequency of the usage of the lexeme. General index of range is average of 5 data from 5 dictionaries for a lexeme.

In Etymological dictionary of the English language [15] it is mentioned that "negative" as adjective has been used since 1400 in the meaning "expressing refusal, denial from Old French "negative" immediately from Latin "negativus" with the meaning "the one who refuses, disagrees", which, in its turn, developed from "negat" - the Past Participle stem of the verb "negare" in the meaning "to say 'no', deny", which is from "ne" + "aiere" (in Greek meaning "I say".)

Usage of "negative" in the extended meaning (1) "expressing negation" has been observed since 1500 . In the 
meaning (3)"the one, who is characterized by the absence of smth" the adjective has been used since 1560s. Algebraic meaning was fixed in 1670, as a term of Physics, particularly
Electrodynamics, in the meaning "negative" it has been used since 1755 .

Table 1. A comparative analysis of the definitions of the adjective "negative'.

\begin{tabular}{|c|c|c|c|c|c|c|}
\hline $\begin{array}{l}\text { Range } \\
\text { General }\end{array}$ & The word meaning & \begin{tabular}{|c|} 
Oxford Ad- \\
vanced Learn- \\
er's Diction- \\
ary \\
\end{tabular} & $\begin{array}{l}\text { Collins Cobuild } \\
\text { Advanced } \\
\text { Learner's Dict. }\end{array}$ & \begin{tabular}{|c|} 
Oxford Student's \\
Dict. of Current \\
English (Hornby \\
1984 ) \\
\end{tabular} & $\begin{array}{l}\text { New Web- } \\
\text { ster's Dict. } \\
\quad(1993)\end{array}$ & $\begin{array}{l}\text { Chamber's Twenti- } \\
\text { eth Century Dict. } \\
\text { (Macdonald, 1972) }\end{array}$ \\
\hline $\begin{array}{c}\mathbf{2} \\
(2)\end{array}$ & $\begin{array}{l}\text { Unpleasant, lacking in helpful qualities, } \\
\text { harmful }\end{array}$ & 2 & 1 & 2 & 2 & 3 \\
\hline $\begin{array}{c}3 \\
(2,6)\end{array}$ & $\begin{array}{l}\text { Considering only bad aspects of a } \\
\text { situation, depressing, not having an } \\
\text { interested attitude to improve }\end{array}$ & 2 & 2 & 2 & 3 & 4 \\
\hline $\begin{array}{c}\mathbf{1} \\
(1,4)\end{array}$ & $\begin{array}{l}\text { Indicating the answer "no", expressing } \\
\text { denial, refusal }\end{array}$ & 1 & 3 & 1 & 1 & 1 \\
\hline $\begin{array}{c}4 \\
(3,8)\end{array}$ & $\begin{array}{l}\text { Containing words such as never, not, } \\
\text { nothing (grammar, logics) }\end{array}$ & 1 & 5 & 1 & 10 & 2 \\
\hline $\begin{array}{c}\mathbf{5} \\
(4,6) \\
\end{array}$ & \begin{tabular}{|l|l|}
$\begin{array}{l}\text { Showing no evidence of smth (in } \\
\text { medicine) }\end{array}$ \\
\end{tabular} & 3 & 6 & - & 4 & 5 \\
\hline $\begin{array}{c}\mathbf{8} \\
(7,2) \\
(7,2)\end{array}$ & $\begin{array}{l}\text { Showing dark areas as light and light } \\
\text { areas as dark (in photography) }\end{array}$ & 7 & 7 & 5 & 8 & 8 \\
\hline $\begin{array}{c}7 \\
(6,4) \\
\end{array}$ & $\begin{array}{l}\text { Having the same electric charge as an } \\
\text { electron (in physics) }\end{array}$ & 5 & 8 & 4 & 7 & 7 \\
\hline $\begin{array}{c}\mathbf{6} \\
(5,6) \\
(5,6)\end{array}$ & $\begin{array}{l}\text { Which is measured by substracting } \\
\text { from } 0 \text {, less than } 0 \text { (in mathematics) }\end{array}$ & 4 & 9 & 3 & 5 & 6 \\
\hline $\begin{array}{c}9 \\
(8,5)\end{array}$ & $\begin{array}{l}\text { Opposite to a direction regarded as } \\
\text { positive (in biology) }\end{array}$ & & & & 6 & 11 \\
\hline $\begin{array}{c}\mathbf{1 2} \\
(10,5)\end{array}$ & $\begin{array}{l}\text { Relating to a movement away from a } \\
\text { stimulus (in physiology) }\end{array}$ & & & & 9 & 12 \\
\hline 11 & $\begin{array}{l}\text { Having the index of refraction for the } \\
\text { extraordinary ray less than for the } \\
\text { ordinary in double refraction (optics) }\end{array}$ & & & & & 10 \\
\hline 10 & Acid (in chemistry) & & & & & 9 \\
\hline
\end{tabular}

So, enrichment of the lexeme "negative" from 1 to 5 lexico-semantic variants coincides with chronological data of the etymological dictionary that reflects science and technology progress outcomes and social changes of humanity.

As for the question of connotation, whether "negative" was used as adjective of negative assessment with the tint of the meaning "bad" in the language and time period the word was borrowed, we haven't traced any evidence. We believe, that this, as well as the fact of existence of the interpreter's false friends, is another evidence that connotative and emotional aspects of the word meanings develop in the course of the word functioning immediately within the language it is borrowed into, but don't "come ready" from the language of borrowing. In our opinion, the notion of the main (semantic) meaning coincides with the sense of the Latin "conceptum" that is "concentrated substance, the main thing".

Connotative component fixes as a result of specific functioning of the word, for example, its frequent usage in the context connected with the collective negative experience, or as a result of accumulation of subjective interpretation of a situation or world vision of individuals, who use the word. It is well known that the systems of values of different cultures are different, thus collective experience of their representatives is different.

In the structure of the dictionary sememes (word meanings) are presented according to their frequency of usage in speech from most frequent to least frequent. On comparing the definitions of "negative" and considering the order of presenting sememes in every of the dictionaries we can formulate the following.

a) Quantity of the sememes and the way they are formulated is very similar, including the same semes in different dictionaries; the biggest quantity of meanings of "negative" as adjective (13) is in Chamber's Twentieth Century Dictionary, least (6) - in Oxford Student's Dictionary of Current English, that is proportional to the dictionary volume and correlates with the date of comprising the dictionary, - fixes discoveries in different branches of science; lexical unit "negative" in average possesses 10 $((8+11+6+11+13): 5=9,8 \approx 10)$ main meanings.

b) In most dictionaries the main 1-range meaning is "indicating the answer "no", expressing denial, refusal," that is equivalent to grammatical interpretation "containing words such as never, not, nothing; the meaning of the $2^{\text {nd }}$ range "unpleasant, lacking in positive qualities, harmful; then comes the $3 \mathrm{~d}$ range meaning "depressing, not having an interested attitude to improve;

c) In most dictionaries beginning with the $4^{\text {th }}$ position the word reveals the meanings, which are elements of different sciences; the usage frequency (the range) vary in different dictionaries and depends on genre of the texts, on which the dictionary was compiled.

d) As a component of scientific terminology "negative" in the order of reducing frequency of usage reveals such meanings:

- in grammar and logics : "containing negative words "never", "not", "nothing";

- in medicine: "showing no evidence of smth.";

- in mathematics: "less than 0";

- in physics: "having the same electrical charge as an electron; - in photography: "showing dark areas as light and light areas as dark;

- in biology: "opposite to a direction regarded as positive"; - in chemistry: "acid"; 
- in optics: having the index of refraction for the extraordinary ray less than for the ordinary in double refraction;

- in physiology: relating to a movement away from a stimulus.

As noun "negation" means "absence of smth or opposition".

The verb "to negate"means 1) to cancel the effect of something, to nullify something, 2) to deny the existence of somebody or something.

In most explanatory dictionaries of the English language there are 5 main lexical meanings of the adjective "negative". At least three of them are used in linguistic terminology, for example, "negative morpheme", "negative connota- tion", "negative prefix". Interference of terminology of new linguistic branches facilitated admitting the extended paradigm of negative affixes. However, taking into consideration different attitude of linguists towards the status of pejorative prefixes and prefixes of opposition we shall restrict the definition to the formulation "affixes with negative implication, which list the following: un-, in- (il-, im-, ir-), a-, dis-, mis-, re-, de-, counter- (contr-), anti-, pseudo-, false-, mal-, non-, less, among which we distinguish proper negative: un-, in- (il-, im-, ir-), a-, dis-.

2) Our attempt to construct a diachronic paradigm of the negative affixes in the English language is presented in the table below.

Table 2. Evolution of negative affixes paradigm.

\begin{tabular}{|c|c|c|c|c|c|}
\hline Period & Group I & Group II & Group III & Group IV & Group V \\
\hline $\mathrm{OE}$ & - & $\begin{array}{l}\text { un-, } \\
\text { wan-, } \\
\text {-læs }\end{array}$ & $\begin{array}{l}\text { mis-, } \\
\text { for-. }\end{array}$ & un- & $\begin{array}{l}\text { gain-, } \\
\text { wip- }\end{array}$ \\
\hline Early MidE & - & $\begin{array}{l}\text { un-, } \\
\text {-læs } \\
\end{array}$ & $\begin{array}{l}\text { mis-, } \\
\text { for-, }\end{array}$ & un- & wip- \\
\hline ModE & $\begin{array}{l}\text { re- } \\
\text { de- }\end{array}$ & $\begin{array}{l}\text { un-, } \\
\text { in-, } \\
\text { (il-, } \\
\text { ir-, } \\
\text { im, } \\
\text { a-, } \\
\text { non- } \\
\text {-less }\end{array}$ & $\begin{array}{l}\text {-mal, } \\
\text {-pseudo }\end{array}$ & $\begin{array}{l}\text { un-, } \\
\text { de-, } \\
\text { dis- }\end{array}$ & $\begin{array}{l}\text { counter- } \\
\text { (contr-), } \\
\text { anti- }\end{array}$ \\
\hline
\end{tabular}

To the Old English paradigm of affixes with negative implication belonged wan-, un-, mis-, for-, wiP, gain-, -læs, for example, wanscelig, miscwePan, fordeman, wiPsegen.

In Early Middle English period the corresponding group included un-, mis-, for-, -laes, wip, for example, unwit, misdede, forwerfcen, skillaes.

Evidently, there are 5 lexical tints of negation (as well as 5 basic lexical meanings of the adjective "negative"), which are rendered by corresponding negative affixes. That's why it's rational to classify negative affixes according to the criteria of main lexical component of negation:

- (group I) affixes with the semantic component of refusal or rejection (etymologically with the meaning of detachment in late French borrowings) re-, de-, for example, repulse, refuse, deny;

- (group II) affixes with semantic component of absence or lack of quality: a-, un-, in- (il-, im-, ir-), non-, for example, unknown, imperfect, helpless, apolitical);

-(group III) affixes with semantic component "bad", "false": mis-, mal-, pseudo-, for example, misspell, pseudogothic, malcontent;

- (group IV) affixes with semantic component of reverse action un-, de-, dis-, for example, unbind, disqualify;

- (group V) affixes with semantic component of opposition: counter- (contr-), anti-, for example, contradict, counterpart.

The table brings a classification of affixes with negative implication in three periods of the English language. Affixes preserve semantics and combinability of the lexical units they were once formed of. Thus, to specify their meanings it's logical to consider their etymology.

Group I. Affixes of Group I were formed from the words which denoted departure, rejection, not receiving smth by the speaker. Dis- (its other forms des-, de-, di-, dif-, s-) was borrowed from Latin with the meaning "away"; it shouldn't be mixed up with dis- (its other form bis-) with the meaning "apart", that was formed from Latin "duo" "two". It's quite possible that from the meaning of polarity and detachment the meaning of rejection developed or visa versa.

Prefix re- with negative meaning appeared in English in Late Middle English in French borrowings [4, p.274] (for example, renounce) and preserved its suchlike meaning in synonymic group of "reject".

Group II. All the affixes of the group II except -less developed from Indo-European ne/n-: OE un-, German and Gothic un-, Swedish o-; un- was general Germanic negative prefix, Greek an-, a-, Latin in- [6, p.213] (im- before labial consonants, $i r$ - before $\mathrm{r}$, $i l$ - before 1 was borrowed in Middle English period from French, to which it came from Latin $a$-, an-, borrowed from Greek via Latin (for example, anarchy).

The prefix wan-belonged to the same group. It was very productive in Old English period, lost its productivity in Middle English and in Modern English was substituted by un-. Wan- comes from Anglo-Saxon wann (black, dark) [13, p.736], from which the verbs to wane (to decrease, to fail), to want developed. There are corresponding adjectives in Celtic (for example, in the Irish language fawn - weak), Scandinavian and Germanic (for example, German - wiht). Wancombined with all notional parts of speech, as well as un-, that contributed to its complete substitution by un-. For example, wanhalp - "unhealthiness", wanhliete - " devoided", wansalig- "unhappy”. It is possible, that un-derives from wan-.

Suffix -less preserves semantics of comparative degree of Old English laessa - "little" and comes from Indo-European root les "weak", from which Indo-European root laes "to reduce", "disappear" derived.

Group III. Affixes of this group render the meaning of negative assessment. Prefix mis- appear in all Germanic languages: in Icelandic mis-, in Swedish miss-, in German missa- with the meaning "wrong". In Old Saxon it was rather productive: miscwefcan - speak incorrectly, curse, misdoneact wrongly, misgiaman - "neglect", mislar - "bad teach- 
ing", mislibban - "lead bad life". The prefix preserves semantic tint of the Scandinavian word with the meaning "to fail to hit", "to omit", from which it derives, Anglo-Saxon missan [14, p.379] is of the same root. Some words with this prefix are of Scandinavian origin: mistake, misbecome, misdeed, misdeem, misdo, misgive, mislay, misbehave, misunderstand, or of French origin (from Latin), for example, misapply, misappropriate. However we should see the difference between Germanic mis- and French mes-, which under the influence of mis- got the English variant of spelling. Mes- comes from the Latin minus "less" and render negative assessment as in the words misadventure, misalliance, mischief.

Pseudo-comes from the Greek noun with the meaning "false", but immediately into English it was borrowed from French.

Mal- was borrowed from French and first fixed in English in G. Chaucer's works. The prefix preserves the semantics of Anglo-Saxon adverb male (badly), from which it derives.

Prefix for- is not registered in grammars as negative, though analysis of antonymic pairs, contextual analysis, as well as correlation of Old English for- with modern disprove this suggestion. In Anglo-Saxon dictionaries there are many antonymic pairs with for-, for example, feran "go"forferan "perish", сиP "well-known", "famous" - forcuP "wicked", cwePan "speak of smb" - forcwePan "rebuke", deman "judge well", "glorify" - fordeman "condemn", don "build" - fordon "destroy", bugan "bow down" - forbugan "avoid". L. I. Blakeley in his comments to forweorPan remarks "... the for-prefix usually gives the sense of destruction or modifies in a bad sense." [1, p.23]

H. Sweet emphasizes the reinforcing component in the semantics of for-: "It is quite distinct from the preposition for, it expresses destruction, loss as in forbarnan "burn up". However, in the beginning of Middle English in the text of "Ormulum" for- gains negative semantics in a group of verbs, which denote relation and corresponds to modern dis-, for example, forwerPan "despise", "neglect", forlaten "disregard", forglopned "disturbed", though in most words the prefix preserves the implication of reinforcement. (far/fur) from Indo-European Por/Dro with the meaning "to put in front of smth" [6, p.76], from Old English for in the meaning "movement". English for- corresponds to Danish for-, Swedish för-, German ver-, Gothic fra-. It is different from fore-, though comes from the same etymon. In the dictionary of Old French it is mentioned, that the prefix forserves for forming verbs with negative meaning [4, p.119]. In the Irish language for-, foir- means: 1) over, hyper, be-
Etymologically for- comes from Germanic root for

yond, extreme, 2) act of stopping, restraining, [1, p.82] [11, p.483]. We can resume that for-gained negative implication as a result of remoting of the doer of the action in the scope of beyond his/her reach, that makes the action be interpreted as absent or stopped or completed with the negative result. The fact, that in German the prefix ver-realizes negation as one of the meaning components is another proof of our suggestion: “...falsch, zum schlimmen in abweichend the meaning verdrucken, sich verlesen, verkalkulieren) Konkuriert noch mis- in Bedeutung: Z.b einerseits ver-/mis-achten.

Group IV. Reversative meaning of un- in English verbs developed from negative in forms of Participle II, e. g., unbound, de-with the meaning of the reversative action, borrowed from French verbs, e. g, to degrade, to demobilize.

Latin prefix of contradiction contra- occur in the words of Latin origin, for example, contradiction, and in he form of counter- in the words of the English origin, e. g., counterpart.

Anti-, ant- was borrowed into English from Greek via Latin with the meaning "against", "opposite". This prefix is productive in Modern English.

$W i P$ - comes from the Old English preposition wiber (against) or the same adjective meaning "adverse". The prefix lost its productivity in the beginning of the Middle English period, though is preserved in the words withstand, withsay.

So, negation on the lexical level is rendered with the help of affixes, which have both explicit and implicit components of negation in their semantics. Authentic affixes preserve semantic meaning of the word, from which it etymologically derives, giving some definite implication to the word it is added to. The main source of broadening the paradigm of affixes and its enrichment with the new meanings are affixes in borrowings.

The paradigm of affixes with negative implication in English has been broadening. Some elements have lost their word forming function (for example, prefix for-), new elements appeared instead. In comparison with Old English the paradigm under study has increased from 8 to 17 . The most productive negative affix in Old English and Early Middle English was un-, however, during active borrowing of French words with prefixes dis- and in- the word forming function of un- was somewhat hampered.

The arguments, presented above, prove our suggestion and enables us to draw the conclusion, that the implications (tints of the meaning) of the affixes under study correspond to the lexical meanings of the adjective "negative", that is a vivid demonstration of the regularity, which linguists call "isomorphism of different language levels".

\section{REFERENCES}

1. Blakeley L. Teach Yourself Old English. London: The English University Press LTD, 1968. - 187 p.

2. Chamber's Twentieth Century Dictionary by Mcdonald. - Publisher's Private Limited. - $1651 \mathrm{p}$.

3. Collins Cobuild Advanced Learner's Dictionary of Current English. 4-th Edition. - Express Publishing, 2003. - 1712 p.

4. Dictionary of the Old French Language. Moscow - Leningrad: AS USSR, 1955

5. Leontjeva S. Negative Affixes in the Modern English Language. Moscow: Vyshaya Shkola, 1974. - 103 p.

6. Levitsky V. An Etymological Dictionary of Germanic Languages (in 2 volumes). Vinnitsa: Nova Knyha, 2010. - V.II - 368 p.

7. Levitsky V. Semasiology. Vinnitsa: Nova Knyha, 2006. - 512 p.

8. New Webster's Dictionary. 3-d college edition. Webster's New World. - Lexicon Publishers, 1993. - 1574 p.
9. Oxford Advanced Learner's Dictionary of Current English. (Ed. by A. S. Hornby, A. Cowie, J. Crowther).-Oxford, 1995.-1438 p. 10. Oxford Student's Dictionary of Current English by A. S. Hornby. Special Edition for USSR. Oxford University Press, 1984.

11. Patrie R., Dinneen,S. Irish-English Dictionary. Dublin, 1927.

12. Quirk R., Greenbaum S., Leech G.. A Grammar of Contemporary English. - Longman Group LTD, 1972. - 1120 p.

13. Skeat W. An Etymological Dictionary of the English Language. - Oxford: At Clarendon Press, 1910.

14. Sweet H. The Student's Dictionary of Anglo-Saxon. - Oxford: At Clarendon Press, 1910.

15. Universal Etymological www.fromoldbooks.org/NathanBailey. 